MATEC Web of Conferences 37, 01047 (2015)

DOI: $10.1051 /$ matecconf $/ 20153701047$

C) Owned by the authors, published by EDP Sciences, 2015

\title{
DEPOSITION AND INVESTIGATION OF HYDROPHOBIC COATINGS
}

\author{
Aleksey Safonov ${ }^{1}, V$ Veronika Sulyaeva ${ }^{2}$, a , Nikolay Timoshenko ${ }^{1}$, Elizaveta Gatapova ${ }^{1}$, Oleg Kabov ${ }^{1,3}$, \\ Ekaterina Kirichenko ${ }^{1}$, Andrey Semenov ${ }^{1}$ \\ ${ }^{1}$ Kutateladze Institute of Thermophysics SB RAS, 630000 Novosibirsk, Russia \\ ${ }^{2}$ Nikolaev Institute of Inorganic Chemistry SB RAS, 630000 Novosibirsk, Russia \\ ${ }^{3}$ National Research Tomsk Polytechnic University, 634050 Tomsk, Russia
}

\begin{abstract}
The fluoropolymer coatings of different morphologies are deposited by the HWCVD (Hot Wire CVD) method. The effect of activator filament temperature on the structure of fluoropolymer coating is shown. The results of studying the hydrophobic fluoropolymer coatings with different structures, deposited by the HWCVD method, are presented.
\end{abstract}

\section{Introduction}

The application of surfaces with controlled hydrophobicity leads to a change in the nature of twophase flow [1-3], hydraulic resistance [4,5], critical heat flux [6,7], as well as condensation [8] and evaporation [9], and this significantly improves the heat exchangers performance.

In order to achieve the superhydrophobic properties of the surface, it is necessary to give low surface energy and nano- or microscale roughness to the material. The examples of the promising surfaces are those produced by means of lithography, etching, deposition of films of the sublimable materials, and laser structuring or mask growth of symmetrical cluster structures with different wetting [10].

Dependence of surface wettability on roughness can be obtained from the Cassie and Baxter law [11], which defines the value of macroscopic equilibrium contact angle $\theta_{c}$ in the case of inhomogeneous surface:

$$
\cos \theta_{c}=\gamma \cdot(\cos \theta+1)-1
$$

where $\theta$ is the contact angle for a smooth surface, $\gamma$ is a part of surface contacting with a droplet of wetting liquid. It is obvious that for low $\gamma$ and high $\theta$, the surface with high contact angles can be created. Therefore, roughness amplifies the hydrophilic nature of the surface due to the capillary effect and makes the hydrophobic surface even more hydrophobic.

In this paper, we present the method of producing hydrophobic coatings with different micro- and nanostructures on the silicon and copper substrates, as well as the results of measurements of contact angles by the DSA-100 KRUSS.

a Corresponding author: vika@itp.nsc.ru 


\section{Experimental setup and research techniques}

In this study, the fluoropolymer coatings with various micro- and nanostructures were deposited by the HWCVD method, based on the use of heated metal catalyst surfaces, such as wire meshes, to activate the precursor gas [12-14]. The schematic diagram of experimental setup is shown in Fig. 1. Hexafluoropropylene oxide $\mathrm{C}_{3} \mathrm{~F}_{6} \mathrm{O}$ was used as the precursor gas of the fluoropolymer film. The cooled substrate holder with the diameter of $90 \mathrm{~mm}$ was in the center of the chamber, and substrates were fixed there. Above the substrates at a distance of $50 \mathrm{~mm}$, there is the catalytic activator in the form of a mesh of spiral-coiled nichrome wire with the diameter of $0.45 \mathrm{~mm}$, with the width of 120 $\mathrm{mm}$, length of $80 \mathrm{~mm}$ and pitch of $8 \mathrm{~mm}$, respectively. The temperature of the mesh was constant and it was monitored by a thermocouple and by electrical resistance. The silicon (111) and copper wafers substrates with the size of $15 \times 15 \mathrm{~mm}^{2}$ were used. The precursor gas pressure in the deposition chamber was 0.5 Torr. The precursor gas flow rate is $100 \mathrm{sccm}$. The temperature of activating mesh $t_{f}$ varied in the range from $650{ }^{\circ} \mathrm{C}$ to $900{ }^{\circ} \mathrm{C}$, the target temperature was about $30{ }^{\circ} \mathrm{C}$.

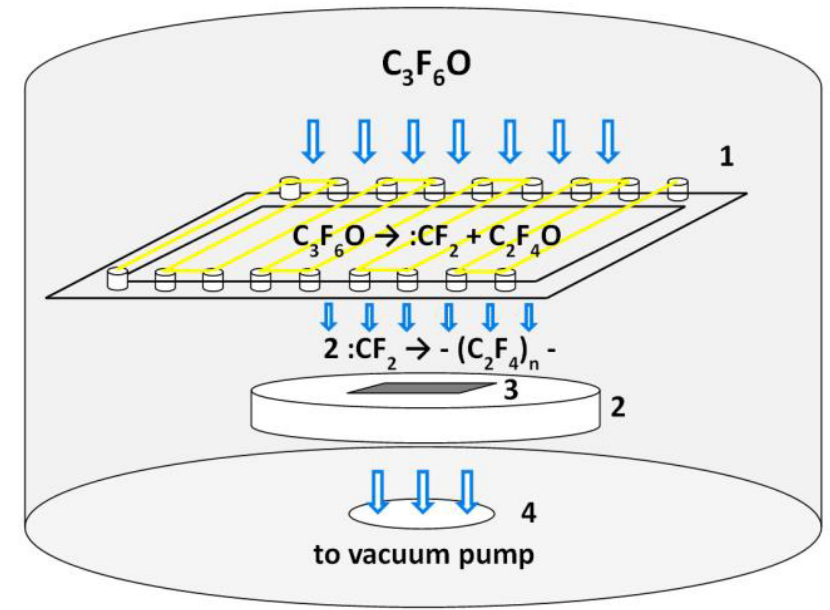

Figure 1. The scheme of Hot Wire CVD method: 1 - wire activator of precursor gas; 2 - substrate holder with water cooling; 3 - silicon (111) and copper substrates; 4 - vacuum-pumping system

The surface morphology and coating thickness were determined by the methods of scanning electron microscopy (SEM) using the JEOL JSM-6700F microscope. The mass of fluoropolymer were determined by substrate weighting before and after deposition. The densities of coatings were determined using their measured masses and thicknesses.

The contact angle of the coating with water was measured by DSA-100 KRUSS device with highprecision system of liquid supply with a minimal dosing step of $0.1 \mathrm{mcl}$. The video system of this device includes: digital CCD - camera with IR filter, resolution of $780 \times 580$ pixels, frame frequency of up to $60 \mathrm{~Hz}$, field of view from $3.7 \times 2.7 \mathrm{~mm}^{2}$ to $23.2 \times 17.2 \mathrm{~mm}^{2}$, spatial resolution of $4.7 \mu \mathrm{m} /$ pix.; optic system, and diffusion halogen light source $(50 \mathrm{~W})$.

The droplet shape was determined by two main methods: tangential and Young-Laplace ones. The tangential method selects the contour of a sessile drop for the equation of conical sectors. The derivative of this equation at the point of intersection of the contour line with the baseline gives the tangent slope at the point of three phases contact, thus, the contact angle. The Young-Laplace method is one of the most accurate methods for calculating the contact angle. This method estimates the full contour of a droplet; the selection takes into account not only the interfacial interactions that define the droplet outline, but also the fact that the droplet is deformed due to the weight of liquid. After the successful selection of the Young-Laplace equation, the contact angle is determined as the slope of the tangent at the point of three phases contact. The model assumes the symmetric shape of a droplet. 


\section{Investigation results}

The typical electronic photographs of the obtained fluoropolymer surface coatings are shown in Fig. 2 depending on the temperature of activator filament. The structure of coating changes from the smooth to the porous one. Depending on the regime of fluoropolymer deposition, the following parameters change: density from 0.8 to $2.4 \mathrm{~g} / \mathrm{cm}^{3}$ and deposition rates from $6 \mathrm{~nm}$ to $\sim 5100 \mathrm{~nm} / \mathrm{min}$.

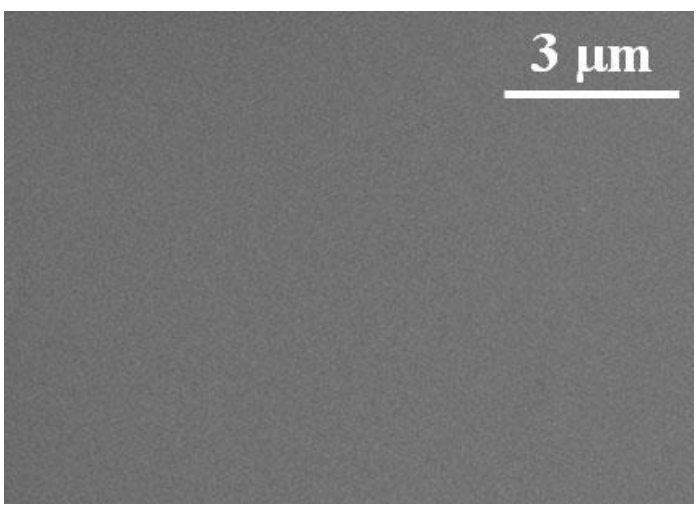

$a$

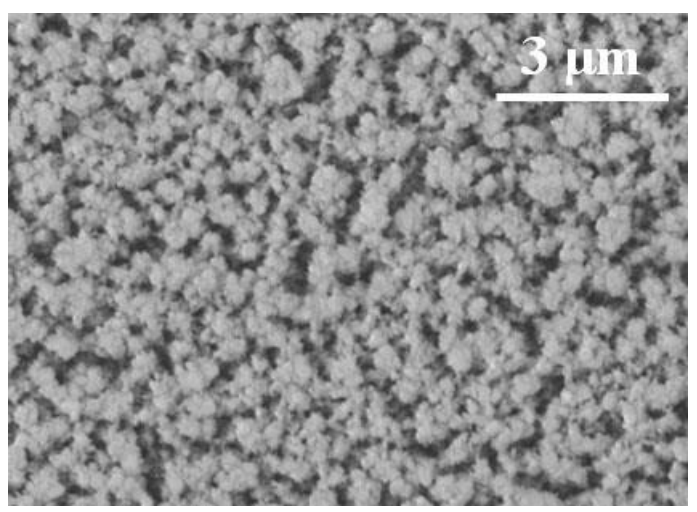

$c$

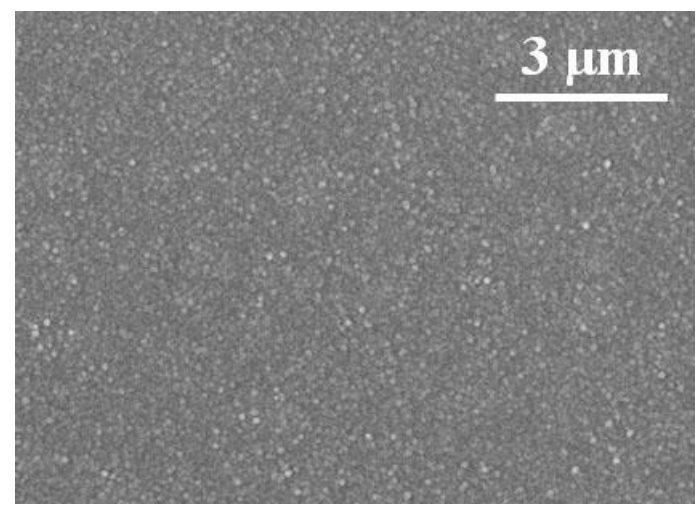

$b$

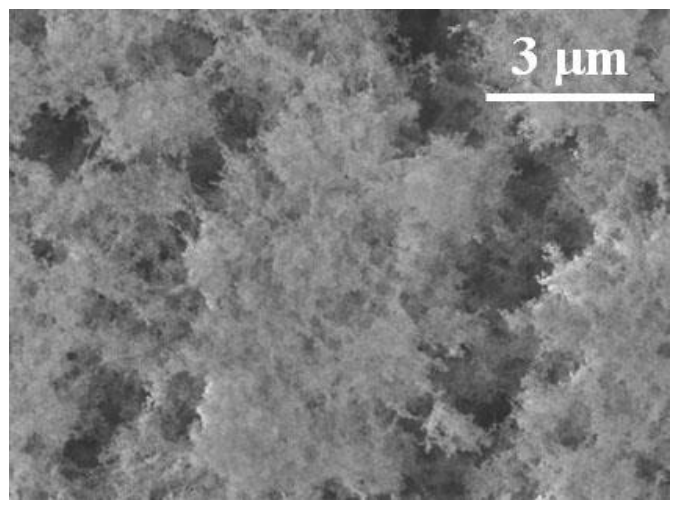

$d$

Figure 2. Morphology of fluoropolymer coating surface at the given temperature of activator filament: (a) $t_{f}=$ $650{ }^{\circ} \mathrm{C}$, deposition rate of $6 \mathrm{~nm} / \mathrm{min}$; (b) $t_{f}=700^{\circ} \mathrm{C}$, deposition rate of $14 \mathrm{~nm} / \mathrm{min}$; (b) $t_{f}=840^{\circ} \mathrm{C}$, deposition rate of $358 \mathrm{~nm} / \mathrm{min}$; (d) $t_{f}=900{ }^{\circ} \mathrm{C}$, deposition rate of $5100 \mathrm{~nm} / \mathrm{min}$.

Results of investigations performed on a silicon substrate by the DSA-100 KRUSS are shown in Fig. 3. The contact angle of water droplet on a surface for pure polished silicon is $55^{\circ}$ (a), and for copper it is $105^{\circ}$. According to the studies, after deposition of a fluoropolymer coating, their contact angle varies in the range from $115^{\circ}$ to $172^{\circ}$ for the silicon substrates and from $130^{\circ}$ to $174^{\circ}$ for the copper ones. The diagram of a change in the contact angle vs. activator filament temperature is shown in Fig. 4. We can observe an increase in the contact angle with increasing temperature of the activator filament. However, there exists the temperature of fluoropolymer coating deposition, when the maximal contact angle is achieved; a further increase in temperature leads to a decrease in the contact angle. This effect requires the detailed study in the future. It should be also noted that dependences of the contact angle change on activator filament temperature for the silicon and copper substrates are similar. However, the contact angles of these materials before fluoropolymer deposition differed significantly. 


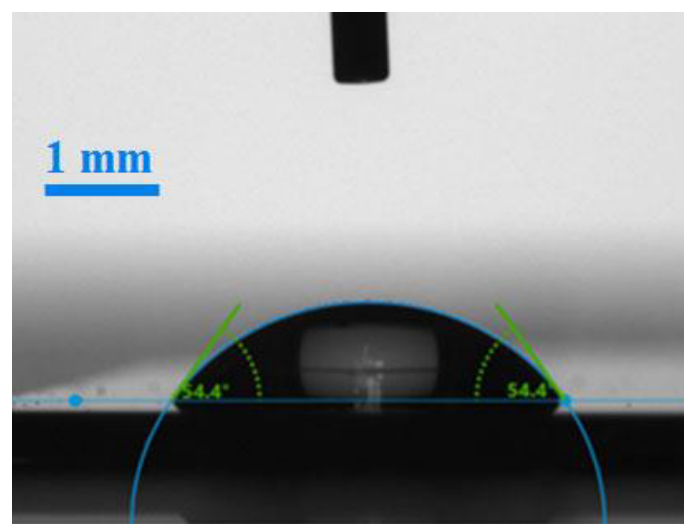

a

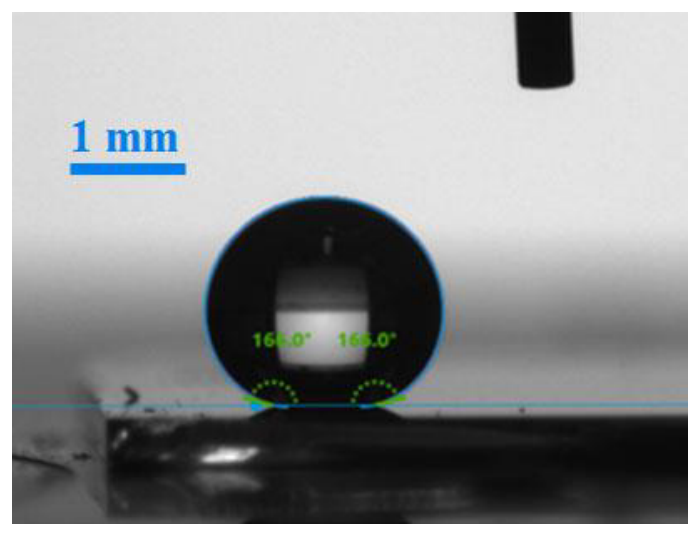

c

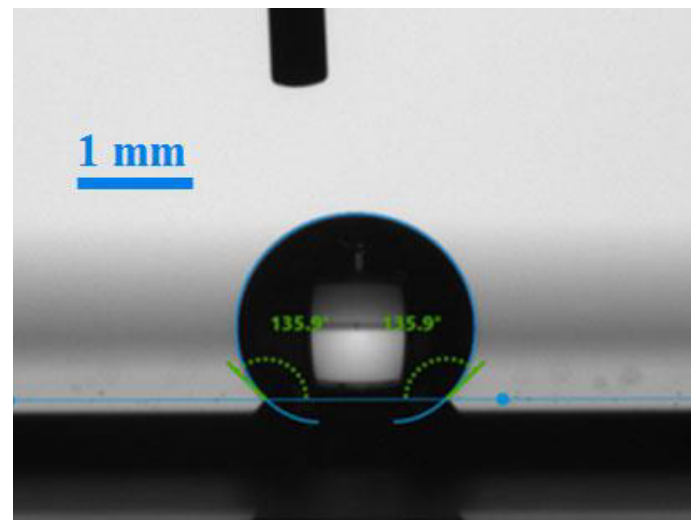

$b$

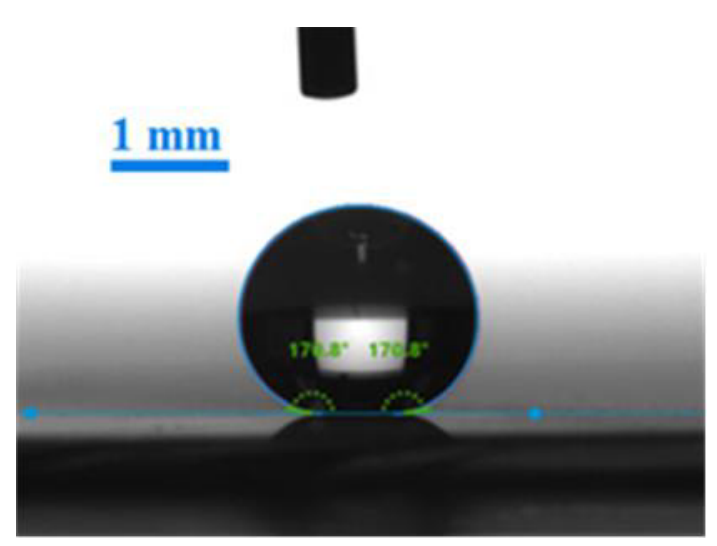

$d$

Figure 3. Water droplets on the silicon surface. Contact angle measurements by DSA-100 KRUSS: (a) before deposition, (b) after deposition of fluoropolymer coating at $t_{f}=700{ }^{\circ} \mathrm{C}$, (c) after deposition of fluoropolymer coating at $t_{f}=840{ }^{\circ} \mathrm{C}$, (d) after deposition of fluoropolymer coating at $t_{f}=900{ }^{\circ} \mathrm{C}$

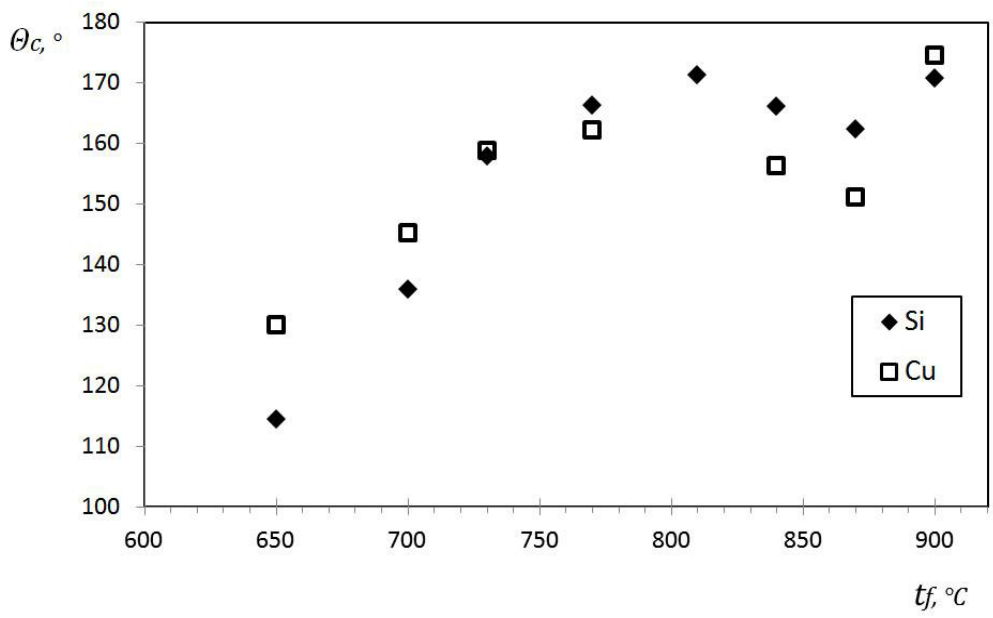

Figure 4. The contact angles change for coatings deposited on the silicon and copper surfaces depending on the temperature of activator filament. 


\section{Conclusions}

The following results are obtained in this study:

- The thin fluoropolymer coatings with different morphologies have been obtained depending on the temperature of activator filament;

- These coatings have different hydrophobic properties;

- The contact angle varies from $115^{\circ}$ to $172^{\circ}$ for the silicon coatings and from $130^{\circ}$ to $174^{\circ}$ for the copper ones;

- Dependences of the contact angle change on the temperature of activator filament for the silicon and copper substrates are similar.

The work was supported by the RFBR grant 15-38-20411 a (the deposition of coatings) and Russian Science Foundation (project No. 14-19-01755) (investigation of surface properties).

\section{References}

1. T. Cubaud, U. Ulmanella, C.-M. Ho, Fluid Dynamics Research, 38, 772 (2006)

2. S. Daniel, M.K. Chaudhury, J.C. Chen, Science, 291, 633 (2001)

3. S. Meyyappan, M.R. Shadnam, A. Amirfazli, Langmuir, 24, 2892 (2008)

4. J. P. Rothstein, Annu. Rev. Fluid Mech., 42, 89 (2010).

5. E.Ya. Gatapova, V.S. Ajaev, O.A. Kabov, JETP Letters, 101(3), 160 (2015)

6. T. J. Hendricks, S. Krishnan, C. Choi, C.-H. Chang, B. Paul, Int. J. Heat Mass Transfer, 53, 3357 (2010)

7. O.A. Kabov, E.Ya. Gatapova, E.A. Chinnov, D.V. Zajtsev, A.A. Semenov, RF Patent No. 2542253 (2015)

8. N. Miljkovic, R. Enright, Y. Nam, K. Lopez, N. Dou, J. Sack, E.N. Wang, Nano Lett., 13, 179 (2013)

9. J.L. Plawsky, A.G. Fedorov, S.V. Garimella, H.B. Ma, S.C. Maroo, L. Chen, Y. Nam, Nanoscale and microscale thermophysical engineering, 18, 251 (2014)

10. L.B. Boinovich, A. M. Emelyanenko, Russ. Chem. Rev., 77, 583 (2008)

11. A. Cassie, S. Baxter, Trans. Faraday Soc., 40, 546 (1944)

12. K. Lau, H. Lewis, S. Limb, M. Kwan, K. Gleason, Thin Solid Films, 395, 288 (2001)

13. K. Kenneth, Y. Mao, H. Lewis, S. Murthy, B. Olsen, L. Loo, K. Gleason, Thin Solid Films, 501, $211(2006)$

14. A. K. Rebrov, A. I. Safonov and N. I. Timoshenko, Technical Physics Letters, 35 (9), 395 (2009) 